Research Article

\title{
Efficacy, tolerability and cost effectiveness of zotepine versus olanzapine in patients of acute schizophrenia
}

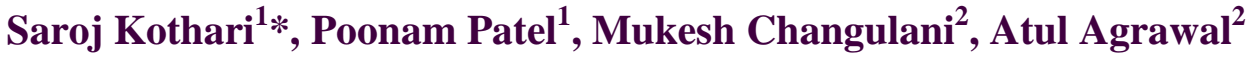

${ }^{1}$ Department of Pharmacology and ${ }^{2}$ Department of Psychiatry, G. R. Medical College, Gwalior, India

Received: 13 August 2013 Accepted: 24 August 2013

*Correspondence to: Dr. Saroj Kothari, Email: saroj.kothari@rediffmail.com

(C) 2013 Kothari S et al. This is an open-access article distributed under the terms of the Creative Commons Attribution Non-Commercial License, which permits unrestricted non-commercial use, distribution, and reproduction in any medium, provided the original work is properly cited.

\begin{abstract}
Background: Schizophrenia is a functional psychosis with severe personality changes and thought disorders without cerebral damage. No reports are available in literature regarding efficacy and tolerability of atypical antipsychotic drug zotepine over olanzapine a preferred drug worldwide for the treatment of schizophrenia. Therefore, present study is undertaken to evaluate efficacy, tolerability and cost effectiveness of zotepine over olanzapine in patients suffering from schizophrenia. Methods: A prospective, randomized, single blind, parallel, 6 weeks clinical study was conducted on a total of 112 patients, of schizophrenia attending psychiatry outpatient department at G. R. Medical College, Gwalior, India randomized into two groups (56 in each). Patients received either olanzapine (10-20mg) or zotepine (75-150mg) per day for a period of 6 week. Efficacy was measured by Positive and Negative Syndrome Scale (PANSS) and Clinical Global Impression (CGI) scale whereas tolerability was measured by dropout rate and frequency of adverse effects. Cost effectiveness was calculated in terms of cost incurred for improvement at the end of treatment period.
\end{abstract}

Results: Both the drugs showed significant $(\mathrm{P}<0.05)$ improvement in PANSS total score as compared to their respective baseline scores however, there was no significant difference between the two groups $(\mathrm{P}>.0 .05)$. Olanzapine showed significantly better $(\mathrm{P}<0.05)$ positive subscale and $\mathrm{CGI}$ scale score improvement as well as response rate when compared to zotepine. Incidences of adverse effects like weight gain, somnolence and hyperglycemia were 42,32 and $12 \%$ respectively with olanzapine and 39, 30 and $9 \%$ respectively with zotepine with no significant difference $(\mathrm{P}>0.05)$ between the two groups. Incidence of akathisia and drop out $(16 \%$ and $23 \%)$ with zotepine were significant $(\mathrm{P}<0.05)$ as compared to olanzapine ( $2 \%$ and $11 \%$ ) respectively.

Conclusions: Though the efficacy of both the drugs is comparable, olanzapine appears to have better tolerability and cost effectiveness than zotepine in patients of schizophrenia.

Keywords: Efficacy, Olanzapine, Schizophrenia, Tolerability, Zotepine

\section{INTRODUCTION}

Schizophrenia, a functional psychosis with severe personality changes and thought disorders without cerebral damage affects approximately 24 million people worldwide. ${ }^{1}$ It is a chronic, debilitating and high treatment cost mental illness, which require ongoing clinical care, rehabilitation, and support services. ${ }^{2}$ The clinical manifestations of the disease include two type of symptomspositive and negative. Positive symptoms are characterised by: delusions, illusions, auditory hallucinations, thought disorders with irrational conclusion, garbled sentences and stereotyped or at times aggressive behaviour. Negative symptoms include: introvert behaviour, poor socialisation, emotional blunting, lack of motivation and cognitive deficits like lack of attention and loss of memory. ${ }^{3}$ Because of better efficacy and less extra pyramidal side effects atypical antipsychotics have an edge over typical antipsychotics worldwide. Among atypical antipsychotics olanzapine is preferred on account of better efficacy but is associated with adverse effects like weight gain, ${ }^{4}$ somnolence, ${ }^{5}$ akathisia ${ }^{6}$ and hyperglycemia ${ }^{7}$ hence, search for safer atypical antipsychotic drug continues. Zotepine is another atypical antipsychotic drug marketed for use since 2010 in India, claimed to be effective for schizophrenia, ${ }^{8,9}$ but there are no reports available in literature regarding how does it differ from olanzapine in the treatment of patients suffering from acute schizophrenia Therefore, present study was planned to 
study \& compare the efficacy tolerability and cost effectiveness of zotepine with olanzapine in the patients of acute schizophrenia.

\section{METHODS}

This prospective, 6 week, open labelled, randomized parallel group comparative study spanning over a period of one year from 2011 to 2012, was conducted in the department of pharmacology and psychiatry, Gajara Raja Medical College and JA group of hospitals Gwalior, India, after obtaining approval of the protocol from institutional ethics committee. After taking detailed informed consent patients were screened for study as per selection criteria and were randomized to the two study groups using an unstratified computer generated randomization list.

Inclusion criteria: The patients between 18 to 60 year of age from either sex suffering from schizophrenia according to DSM-IV diagnostic criteria ${ }^{[10]}$ with PANSS total score of greater than or equal to 60 .

Exclusion criteria: Age out of range, any other psychiatric condition or psychotropic medication prior to entering the study, current history of substance abuse syndrome (except nicotine/caffeine), seizure, diabetes mellitus, hypertension, pregnant/nursing females, hepatic disease or history of same, renal insufficiency and haematological diseases.

Study visit and treatment schedule: A total of 112 patients were randomized into two groups $(n=56$, each), olanzapine treated group $(\mathrm{OZ})$ and zotepine treated group (ZT). Patients of OZ group received tablet olanzapine (Intas Pharmaceuticals, Ahmedabad) $10 \mathrm{mg}$ twice daily and patients of ZT group received tablet zotepine $25 \mathrm{mg}$ tablet (Sun Pharmaceuticals, Mumbai) thrice a day for 4 days and then $50 \mathrm{mg}$ thrice a day for a total period of 6 weeks. Initial readings were considered as baseline, first and second review values were taken at the end of 3 and 6 weeks respectively.

\section{Efficacy assessment}

\section{Positive and Negative Syndrome Scale (PANSS)}

Improvement and response was judged by Positive and Negative Syndrome Scale scores (PANSS). ${ }^{9}$ The PANSS include 30 items on 3 subscales: 7 items covering positive symptoms, 7 covering negative symptoms, and 16 covering general psychopathology symptoms. Each item is scored on a seven-point item-specific Likert scale ranging from 1 to 7 . Thus, both positive and negative subscales range from 7 to 49 each, and the general psychopathology scale range from 16 to 112 giving a total score ranging between 30 and 210. The response was defined by a decrease of $\geq 40 \%$ in PANSS score. ${ }^{11}$

\section{Clinical Global Impression scale (CGI)}

The CGI is an observer rated 7-point scale, which measures severity of illness (CGI-S) using a range of responses from 1 (normal) to 7 (amongst the most severely ill patients) whereas CGI-I scale measures total improvement rate scores ranging from 1 (very much improved) to 7 (very much worse). ${ }^{12}$

\section{Safety assessment}

\section{Simpson-Angus Scale (SAS)}

Extra pyramidal side-effects were measured by SimpsonAngus Scale. It is 10 items observation rated scale. The SAS is rated on a 4-point scale, with a range of responses from 0 (normal) to 4 (amongst the most severely ill patients) after examining both sides of the body. ${ }^{13}$

\section{Barnes Akathisia Rating Scale (BARS)}

Akathisia was measured by Barnes Akathisia Rating Scale at 3rd \& 6th week. Subjective awareness of restlessness and subjective distress related to restlessness are rated on a 4-point scale from $0-3$ and are summed yielding a total score ranging from 0 to $9 .^{14}$

\section{Cost effective analysis}

Two interventions were compared on the basis of total money spent on treatment by the patients in relation to improvement in health during the study period. Initially for both medications one day cost was calculated then the cost was calculated for 6 weeks. Study period cost was divided by minimum improvement value and maximum improvement value to find cost effective range for both the medications. ${ }^{15}$

\section{Statistical Analysis}

Improvement in PANSS per visit in the two groups was compared by unpaired $\mathrm{t}$ test, while the inter group comparison was done by ANOVA. The response \& dropout rates due to adverse events in the two groups were compared by chi-square test. All values were expressed as mean \pm standard error of mean (SEM). $\mathrm{P}<0.05$ was considered as statistically significant.

\section{RESULTS}

Fifty patients in group $\mathrm{OZ}$ and 43 patients in group ZT completed the study. The characteristics of the patients involved in the study are given in Table 1 .

Table 1: Patients characteristics.

\begin{tabular}{|llll|}
\hline S. No. Particulars of the patients & OZ & ZT \\
\hline 1 & Mean age \pm SD (years) & $25.74 \pm 9.5$ & $28.64 \pm 8.6$ \\
\hline 2 & Male: Female (\%) & $63: 37$ & $61: 39$ \\
\hline 3 & Married:Unmarried (\%) & $54: 46$ & $57: 43$ \\
\hline 4 & Rural: Urban (\%) & $33: 67$ & $31 ; 69$ \\
\hline 5 & Unemployed:Employed (\%) & $72: 28$ & $75: 25$ \\
\hline 6 & Use of Substance of abuse (\%) & 54 & 55 \\
\hline
\end{tabular}

$\mathrm{OZ}=$ olanzapine treated group, $\mathrm{ZT}=$ zotepine treated group 


\section{Improvement in PANSS and CGI score}

Group OZ and ZT showed significant $(\mathrm{P}<0.05)$ improvement by 25 and $21 \%$ respectively at the end of $3^{\text {rd }}$ week, and 42 and $37 \%$ respectively at the end of $6^{\text {th }}$ week in total PANSS as compared to baseline scores. On intergroup comparison difference between the two groups at both follow up visits was found to be statistically insignificant $(\mathrm{P}>0.05)$ (Figure 1). Improvement by $\mathrm{OZ}$ and ZT in positive subscale score was 31 and $22 \%$ at the end of 3 weeks which increased to $52 \%$ and $37 \%$ at the end of 6 weeks respectively $(\mathrm{P}<0.05)$ when compared to basal score. This change in group OZ was statistically significant $(\mathrm{P}<0.05)$ as compared with that of group ZT at the end of 3 and 6 weeks (Figure 2). OZ and ZT showed insignificant improvement by $15,20 \%(\mathrm{P}>0.05)$ respectively at the end of 3 weeks and significant improvement by $30,34 \%$ respectively $(\mathrm{P}<0.05)$ at the end of 6 weeks in negative subscale score as compared to basal score. On inter group comparison greater improvement on negative subscale by group ZT over group $\mathrm{OZ}$ was observed and was non- significant $(\mathrm{P}>0.05)$ (Figure 3). On CGI-I scale OZ and ZT showed 21 and $16 \%$ improvement $(\mathrm{P}>0.05)$ after 3 weeks, whereas 56 and $38 \%$ improvement after 6 weeks respectively $(\mathrm{P}<0.05)$ as compared to basal score. Difference in CGI-I scale score between the groups was significant $(\mathrm{P}<0.05)$ (Table 2).

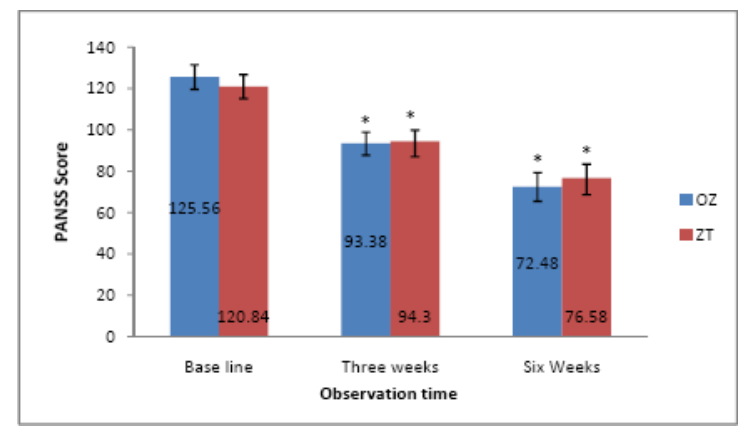

Figure 1: Effect of olanzapine and zotepine on total positive and negative syndrome scale. Data represent mean $\pm \mathrm{SEM},{ }^{*} \mathrm{P}<0.05$ as compared to baseline score.

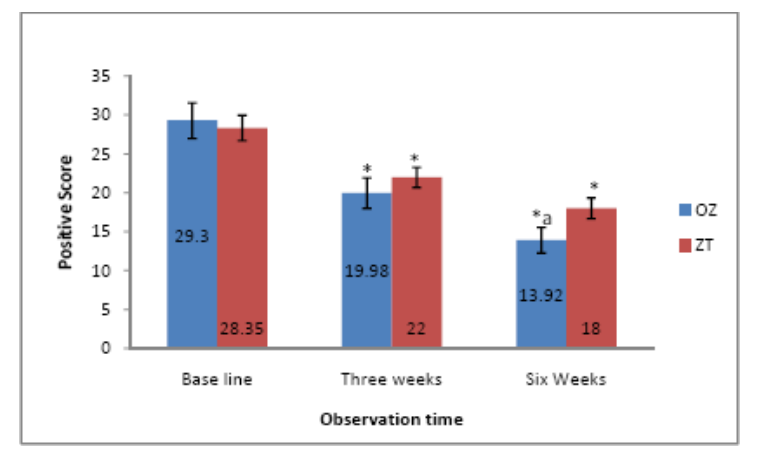

Figure 2: Effect of olanzapine and zotepine on positive subscale score. Data represent mean $\pm \mathrm{SEM}$,

${ }^{*} \mathrm{P}<0.05$ as compared to baseline score, ${ }^{* \mathrm{a}} \mathrm{P}<0.05$ as compared to zotepine at 6 week.

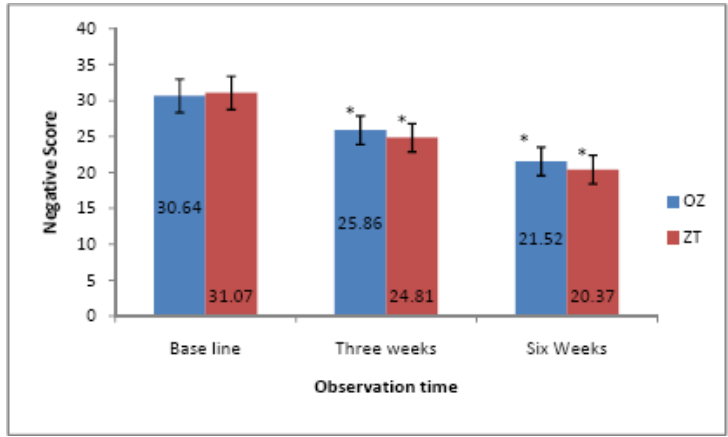

Figure 3: Effect of olanzapine and zotepine on negative subscale score. Data represent mean \pm SEM, $* \mathrm{P}<0.05$ as compared to baseline score.

Table 2: Clinical Global impression- Improvement (CGI- I) score.

\begin{tabular}{|llll|}
\hline \multirow{2}{*}{ Group } & \multicolumn{4}{l}{ CGI-I score $($ mean \pm SEM) } \\
\cline { 2 - 4 } & $\mathbf{0}$ week & $\mathbf{3}^{\text {rd }}$ week & $\mathbf{6}^{\text {th }}$ week \\
\hline OZ $(n=50)$ & $5.94 \pm 0.96$ & $4.42 \pm 0.103$ & $2.64 \pm 0.145^{* a}$ \\
\hline ZT $(n=43)$ & $5.395 \pm 0.1006$ & $4.53 \pm 0.119$ & $3.349 \pm 0.185^{*}$ \\
\hline
\end{tabular}

$\mathrm{OZ}=$ olanzapine treated group, $\mathrm{ZT}=$ zotepine treated group (Student's test $=3.055$, Degree of freedom $=91 .^{*}=\mathrm{P}<0.05$ as compared to 0 week, $\mathrm{a}=\mathrm{P}<0.05$ as compared to zotepine treated group at $6^{\text {th }}$ week

\section{Response}

Decrease of $\geq 40 \%$ in PANSS score was observed in $62 \%$ $(n=35)$ of olanzapine and $44 \%(n=19)$ of zotepine treated patients respectively. On comparison between the two groups OZ group showed significant $(\mathrm{P}<0.05)$ responder rate as compared with that of $\mathrm{ZT}$ group at the end of 6 weeks.

\section{Tolerability}

Assessment of ADRs reported in the two groups was done at the end of 6 weeks as there was no statistical difference between data at the end of 3 and 6 weeks. Weight gain was the most common adverse effect observed in both the groups. Though greater number of patients in group OZ (44\%) showed weight gain than group zotepine $(40 \%)$ yet the difference between the two groups was not statistically significant $(\mathrm{P}>0.05)$ (Table 3 ). Mean weight gain with group $\mathrm{OZ}$ and $\mathrm{ZT}$ was +4.18 $\mathrm{kg}$ and $+2.44 \mathrm{~kg}$ respectively. Somnolence was seen in 32 and $30 \%$ patients among $\mathrm{OZ}$ and $\mathrm{ZT}$ respectively and there was no statistically significant difference between the two study groups. Hyperglycemia was observed in non- significantly higher $(\mathrm{P}>0.05)$ number $(12 \%)$ of patients in group $\mathrm{OZ}$ as compared to $(9 \%)$ in group $\mathrm{ZT}$

Incidence of akathisia was $16 \%$ with group $\mathrm{ZT}$ and $2 \%$ with group OZ. On comparison between two groups it 
was significantly more in group ZT. Change in mean akathisia score, as measured by Barnes Akathisia rating scale was -0.5 for olanzapine and -1.275 for zotepine. The adverse reactions like dizziness, constipation and asthenia 16, 16 and $16 \%$ respectively with olanzapine were more as compared to 8,6 and $10 \%$ respectively with zotepine while the difference between groups was not significant $(\mathrm{P}>0.05)$. Extra pyramidal side effects were seen in $(6 \%)$ patients of olanzapine and only $5 \%$ patients in ZT group. Incidences of other less frequent adverse effects observed were statistically comparable in both study groups and are listed in Table 3.

Table 3: Adverse drug reactions at 3 and 6 weeks after medication.

\begin{tabular}{|c|c|c|c|c|}
\hline \multirow{2}{*}{$\begin{array}{l}\text { Adverse drug } \\
\text { reactions }\end{array}$} & \multicolumn{2}{|c|}{ At 3 weeks } & \multicolumn{2}{|c|}{ At 6 weeks } \\
\hline & $\mathbf{O Z}$ & $\mathbf{Z T}$ & $\mathbf{O Z}$ & ZT \\
\hline Weight gain & 18 & 13 & 22 & 17 \\
\hline Somnolence & 15 & 13 & 16 & 13 \\
\hline Akathisia & 0 & 6 & 1 & 7 \\
\hline Dizziness & 3 & 5 & 4 & 7 \\
\hline Constipation & 2 & 4 & 3 & 7 \\
\hline Asthenia & 3 & 5 & 5 & 7 \\
\hline Dry mouth & 2 & 3 & 4 & 4 \\
\hline $\begin{array}{l}\text { Increased pulse } \\
\text { rate }\end{array}$ & 2 & 3 & 3 & 5 \\
\hline Insomnia & 1 & 4 & 1 & 4 \\
\hline Hyperglycemia & 4 & 3 & 6 & 4 \\
\hline Headache & 3 & 2 & 4 & 3 \\
\hline Dystonia & 0 & 1 & 0 & 2 \\
\hline Hypotension & 0 & 2 & 0 & 2 \\
\hline $\begin{array}{l}\text { Extra pyramidal } \\
\text { symptoms }\end{array}$ & 2 & 2 & 3 & 2 \\
\hline
\end{tabular}

$\mathrm{OZ}=$ olanzapine treated group, $\mathrm{ZT}=$ zotepine treated group

\section{Dropout rate}

A total of $6(11 \%)$ and $13(23 \%)$ patients stopped treatment in group OZ and ZT respectively due to various adverse reactions. On inter group comparison the dropout rate in group $\mathrm{ZT}$ was significant $(\mathrm{P}<0.05)$ as compared to group OZ.

\section{Cost effectiveness}

After 6 weeks of therapy minimum and maximum reduction in PANSS basal total score was 34, 74 with olanzapine and 25, 64 with zotepine respectively. Total cost of treatment with Olanzapine was Rs. 476.28 and zotepine was Rs. 816. Olanzapine was found to be more cost effective than zotepine (Table 4). Table 4: Cost effective analysis of olanzapine and
zotepine medication for 6 weeks.

\begin{tabular}{|c|c|c|}
\hline Treatment & Olanzapine & Zotepine \\
\hline Dosage schedule & $\begin{array}{l}10 \mathrm{mg} \mathrm{bid} / \text { day } \\
\times 42 \text { Days }\end{array}$ & $\begin{array}{l}25 \mathrm{mg} \text { tid/day } \\
\times 4 \text { days }, \\
50 \mathrm{mg} \text { tid } \times 38 \\
\text { days }\end{array}$ \\
\hline $\begin{array}{l}\text { Total dose } \\
\text { required }\end{array}$ & $\begin{array}{l}84 \mathrm{tab} \\
(10 \mathrm{mg} \text { each) }\end{array}$ & $\begin{array}{l}120 \mathrm{tab} \\
(50 \mathrm{mg} \text { each })\end{array}$ \\
\hline Cost per tab (Rs.) & $\begin{array}{l}10 \mathrm{mg} \text { tab }= \\
5.67\end{array}$ & $\begin{array}{l}50 \mathrm{mg} \mathrm{tab}= \\
6.80\end{array}$ \\
\hline $\begin{array}{l}\text { Cost for } 42 \text { days } \\
\text { treatment (Rs.) }\end{array}$ & 476.28 & 816.00 \\
\hline $\begin{array}{l}\text { Max. cost per } \\
\text { PANSS } \\
\text { improvement (Rs.) }\end{array}$ & $\begin{array}{l}476.28 / 34= \\
14.00\end{array}$ & $\begin{array}{l}816 / 25= \\
32.64\end{array}$ \\
\hline $\begin{array}{l}\text { Min. cost per } \\
\text { PANSS } \\
\text { improvement (Rs.) }\end{array}$ & $\begin{array}{l}476.28 / 74= \\
6.43\end{array}$ & $\begin{array}{l}816 / 64= \\
12.75\end{array}$ \\
\hline $\begin{array}{l}\text { Cost range per } \\
\text { PANSS } \\
\text { improvement (Rs.) }\end{array}$ & $6.43-14.00$ & $\begin{array}{l}12.75- \\
32.64\end{array}$ \\
\hline
\end{tabular}

PANSS $=$ positive and negative symptom score, Improvement= reduction in basal PANSS at the end of 6 weeks, min=minimum, $\max =$ maximum, tab=tablet

\section{DISCUSSION}

The selection of an antipsychotic drug to treat patients with schizophrenia is complex decision for which the physician must weigh individual patient's factors and numerous drug factors, including efficacy, safety, tolerability, and cost effectiveness. ${ }^{16}$ Present study revealed that overall improvement in total PANSS is significant with both the drugs as compared to basal score, suggesting that both drugs are efficacious for the treatment of schizophrenia which is in confirmation to earlier reports. ${ }^{17,18}$ Further, olanzapine showed greater decrease in total PANSS score than zotepine suggesting of comparative better efficacy with olanzapine. ${ }^{19,20}$ Significant improvement in positive symptoms with olanzapine as compared to zotepine is suggestive of predominant role of olanzapine in $\mathrm{D}_{2}$ receptor blockade over $5 \mathrm{HT}_{2}$ receptor blockade. ${ }^{21}$ Zotepine showed nonsignificantly better improvement in negative symptoms. This could be attributed to zotepine's predominant $5 \mathrm{HT}_{2}$ receptor blockade over $\mathrm{D}_{2}$ blockade and re-uptake inhibition of nor adrenaline. .1,22 $^{2}$

Significantly greater number of patients showed more than $40 \%$ improvement in PANSS in olanzapine treated group than zotepine treated group. Previous studies also 
reported better responder rate with olanzapine in comparison to other atypical antipsychotic drugs. ${ }^{19,20,23}$

Weight gain was observed as most frequent adverse effect with both the drugs and is in confirmation with earlier reports. ${ }^{24}$ Weight gain due to atypical antipsychotics correlates to an extent with affinity for the $\mathrm{H}_{1}, 5-\mathrm{HT}_{2 \mathrm{C}}$, melanocortinergic, GABAergic, cannabinoid and $\mathrm{M}_{3}$ receptors. $^{25-27}$ Higher number of olanzapine treated patients developed weight gain in present study suggesting implication of olanzapine to a greater extent than zotepine for these receptors. Weight gain was the major cause for dropout in olanzapine treated patients in present study. Somnolence was second most common adverse effects found in both study groups. This is in accordance to previous research indicating higher incidence of somnolence in atypical antipsychotics owing to their higher affinity for $\mathrm{H}_{1}$ receptors than typical antipsychotics. ${ }^{28}$ There was no statistically significant difference in incidence of somnolence between the two groups though clinically more frequent in group olanzapine suggesting its comparatively greater affinity for $\mathrm{H}_{1}$ receptors. Hyperglycemia was observed in nonsignificantly greater number of patients treated with olanzapine than zotepine, this can be attributed to earlier report of $\mathrm{M}_{3}$ blockade by olanzapine causing decrease secretion of insulin ${ }^{27}$ and lesser hyperglycemia with zotepine is suggestive of its less predominant role on $\mathrm{M}_{3}$ blockade than olanzapine.

Though atypical antipsychotics are known to cause akathisia, but greater incidence of akathisia with zotepine than olanzapine in present study might be due to inhibition of dopaminergic neurons that are located in the ventral tegmental area which have significant input from the noradrenergic and serotonergic system as zotepine displays binding affinity for the nor epinephrine transporters. ${ }^{19,29}$ Akathisia was the major cause for dropout in zotepine treated patients as compared to olanzapine treated patients. Other adverse effects which were non significantly greater with zotepine include insomnia, dizziness, asthenia and as compare to olanzapine might be due to blockade of dopaminergic reward system by zotepine similar to earlier report with atypical antipsychotics. ${ }^{30}$ Higher incidence of these adverse effects with zotepine is suggestive of greater efficacy of zotepine in dopaminergic reward system blockade than olanzapine.

\section{CONCLUSION}

There is no significant difference in terms of improvement between olanzapine and zotepine after 6 weeks treatment in patients of acute schizophrenia. However olanzapine appears as better responded and tolerated economical drug than zotepine in control of schizophrenia. Because the study had the limitations of being non- blinded and conducted at a single centre, further confirmations of these observation by multicentre, randomized double-blind large population studies are needed.

\section{ACKNOWLEDGEMENTS}

We are thankful to Dr. Dilip Kothari, Associate Professor in Anaesthesiology, G.R. Medical College, Gwalior, M.P., India for his valuable writing assistance in preparing the manuscript of this study.

\section{Funding: None}

Conflict of interest: None declared

Ethics approval: Approved by the Institutional Ethics Committee

\section{REFERENCES}

1. Sharma HL, Sharma KK. Principles of Pharmacology; Antipsychotic Drugs. First edition, Paras medical publishing. 2007; 35: 459.

2. Adamou M. Community Service Models for Schizophrenia: Evidence-Based Implications and Future Directions. Psychiatry 2005; 2(2): 24-30.

3. Andreasen NC, Olsen S. Negative $\mathrm{v}$ positive schizophrenia. Definition and validation. Arch Gen Psychiatry 1982; 39:789-94.

4. Baptista T, De Mendoza S, Beaulieu S, Bermudez A, Martinez M. The metabolic syndrome during atypical antipsychotic drug treatment: mechanisms and management. Metab Syndr Relat Disord 2004; 2(4): 290-307.

5. Gao K, Ganocy SJ, Gajwani P, Muzina DJ, Kemp DE, Calabrese JR. A review of sensitivity and tolerability of antipsychotics in patients with bipolar disorder or schizophrenia: focus on somnolence. J Clin Psychiatry 2008; 69(2): 302-9.

6. Kumar R, Sachdev PS. Akathisia and second generation antipsychotic drugs. Current opinion in psychiatry 2009; 22 (3):293-99.

7. Kane JM, Barrett EJ, Casey DE, Correll CU, Gelenberg AJ, Klein S, et al. Metabolic effects of treatment with atypical antipsychotics. J Clin Psychiatry 2004; 65(11): 1447-55.

8. Petit M, Raniwalla J, Tweed J, Leutenegger E, Dollfus S, Kelly F. A comparison of an atypical and typical antipsychotic, zotepine versus haloperidol in patients with acute exacerbation of schizophrenia: a parallel-group double-blind trial. Psychopharmacol Bull. 1996; 32:81-7.

9. Cooper SJ, Tweed J, Raniwalla J, Butler A, Welch C. A placebo-controlled comparison of zotepine versus chlorpromazine in patients with acute exacerbation of schizophrenia. Acta Psychiatr Scand 2000; 101(3): 218-25.

10. American Psychiatric Association: Diagnostic and statistical manual of mental disorders: DSM IV-TR American psychiatric publishing 2000.

11. Kay S, Opler L, Lindenmayer J. The Positive and Negative Syndrome Scale (PANSS): rationale and 
standardisation. Br J Psychiatry 1989; 155 (suppl. 7):59 -67.

12. Haro JM, Kamath SA, Ochoa S, Novick D, Rele K, Fargas A, et al. The Clinical Global ImpressionSchizophrenia Scale: A simple instrument to measure the diversity of symptoms present in schizophrenia. Acta Psychiatr Scand. 2003; (416):16-23.

13. Simpson GM, Angus JWS: A rating scale for extrapyramidal side effects. Acta Psychiatrica Scandinavica 1970; 212:11-19.

14. Barnes TRE: A Rating Scale for Drug-Induced Akathisia. Br J Psychiatry 1989; 154: 672-76.

15. Granata AV, Hillman AL. Competing practice guidelines: using cost-effectiveness analysis to make optimal decisions. Ann Intern Med 1998; 128: 5663.

16. Franz M, Ranger J, Hanewald B, Gallhofer B, Lay B. Influences on therapist's decisions for neuroleptic treatment in schizophrenia: the role of characteristics of the patient and the physician. Pharmacopsychiatry 2012; 45(7):261-8.

17. Sanger TM, Lieberman JA, Tohen M, Starr Grundy $\mathrm{PH}$, Beasley $\mathrm{C}$, and Tollefson GD. Olanzapine versus Haloperidol Treatment in First-Episode Psychosis Am J Psychiatry 1999; 156(1): 79-87.

18. Hwang TJ, Lin SK and Lin HN. Efficacy and safety of zotepine for the treatment of Taiwanese schizophrenic patients: a double-blind comparison with haloperidol. J Formos Med Assoc 2001; 100: (12) 811-16.

19. Tran PV, Hamilton SH, Kuntz AJ, Potvin JH, Andersen SW, Beasley CB et al. Double-blind comparison of olanzapine versus risperidone in the treatment of schizophrenia and other psychotic disorders. J Clin Psychopharmacol 1997; 17: $407-$ 18.

20. Fleischhacker WW, McQuade RD, Marcus RN, Archibald D, Swanink R, Carson WH. A doubleblind, randomized comparative study of aripiprazole and olanzapine in patients with schizophrenia. Biol Psychiatry 2009; 65(6): 510-17.

21. Josse E, Paul MFA, Alan S, Walter HML, Anton AHP. Interaction of antipsychotic drug with neurotransmitter receptor site in vitro and in vivo in relation to pharmacological and clinical effects: role of $5 \mathrm{HT}_{2}$ receptors. Psychopharmacology 1993; 112:S40-S55.

22. Tatsumia M, Jansena K, Blakelyc RD, Richelson E. Pharmacological profile of neuroleptics at human monoamine transporters. Eur J Pharmacol 1999;368(2-3):277-83.

23. Simpson GM, Weiden P, Pigott T, Murray S, Siu CO, Romano SJ. Six-month, blinded, multicenter continuation study of ziprasidone versus olanzapine in schizophrenia. Am J Psychiatry 2005; 162(8):1535-8.

24. Albaugh VL, Vary TC, Ilkayeva O, Wener BR, Maresca KP, Joyal JL, et al. Atypical Antipsychotics Rapidly and Inappropriately Switch Peripheral Fuel Utilization to Lipids, Impairing Metabolic Flexibility in Rodents. Schizophrenia Bulletin 2010; 38 (1):153-66.

25. Weston-Green KL, Huang XF, Deng C. Alterations to melanocortinergic, GABAergic and cannabinoid neurotransmission associated with olanzapineinduced weight gain. PloS one 2012; 7(3): e33548.

26. Kirk SL, Glazebrook J, Grayson B, Neill JC, Reynolds GP. Olanzapine induced weight gain in the rat: role of 5-HT2C and histamine $\mathrm{H} 1$ receptors. Psychopharmacology2009;207:119-25 .

27. Weston-Green K, Huang XF, Lian J, Deng C. Effects of olanzapine on muscarinic M3 receptor binding density in the brain relates to weight gain, plasma insulin and metabolic hormone levels. Eur Neuropsychopharmacol 2012;22(5):364-73.

28. Piparva KG, Buch JG, Chandrani KV. Analysis of Adverse Drug Reactions of Atypical Antipsychotic Drugs in Psychiatry OPD. Indian J Psychol Med 2011;33(2):153-7.

29. Catalano G, Grace JW, Catalano MC, Morales MJ, Cruse LM. Acute akathisia associated with quetiapine use. Psychosomatics 2005;46:291-301.

30. Kirsch P, Ronshausen S, Mier D, Gallhofer B. The influence of antipsychotic treatment on brain reward system reactivity in schizophrenia patients. Pharmacopsychiatry 2007;40(5):196-8.

doi:10.5455/2319-2003.ijbcp20131013

Cite this article as: Kothari $\mathrm{S}$, Patel $\mathrm{P}$, Changulani M, Agrawal A. Efficacy, tolerability and cost effectiveness of zotepine versus olanzapine in patients of acute schizophrenia. Int J Basic Clin Pharmacol 2013;2:577-82. 